\title{
Euro Area Money Demand Stability
}

Michael Cosgrove, (Email: cosgrove@gsm.udallas.edu), University of Dallas

Chaitanya Singh, University of Dallas

Maura Sheehan, University of Brighton

\begin{abstract}
The European Central Bank (ECB) has price level stability as its primary target, and operates via an interest-rate measure to achieve its target over the short term. The ECB also explicitly incorporates a quantity measure, M3, into their monetary framework to help assess the medium to longer term risks to price level stability. Use of M3 by the ECB implies a stable relationship between money and prices. We analyzed the behavior of monetary aggregates, and concluded that the ECB's use of M3 may have some merit over the medium to longer-term as an indicator of price pressure from a quantity theory of money perspective. But there appears to be a question as to stability of money demand since it is not clear if there is a constant interest-rate elasticity. So, in practice, it remains unclear if the ECB gives much credence to any of the monetary aggregates. In particular, this applies to M3 since the ECB cannot directly control that measure.
\end{abstract}

\section{INTRODUCTION}

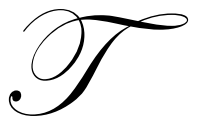

he primary objective of the ECB's monetary policy is to maintain price stability. The ECB aims at inflation rates of below, but close to, $2 \%$ over the medium term. In the Treaty establishing the European Community its “ ... provisions also imply that, in the actual implementation of monetary policy decisions aimed at maintaining price stability, the Eurosystem should also take into account the broader economic goals of the Community. In particular, given that monetary policy can affect real activity in the shorter term, the ECB typically should avoid generating excessive fluctuations in output and employment if this is in line with the pursuit of its primary objective."

The ECB does have its primary objective clearly stated as price stability while, in comparison, the Federal Reserve has targets of both stable prices and maximum employment. Moreover, as in Scheller (2006), "The ECB's monetary analysis relies on the fact that monetary growth and inflation are closely related in the medium to long run or that the relationship is stable. Assigning money a prominent role therefore underpins the medium-term orientation of the ECB's monetary policy strategy." Further, "to signal its commitment to monetary analysis and provide a benchmark for the assessment of monetary developments, the ECB has announced a reference value for the growth of the broad monetary aggregate M3." The target for the rate of growth in M3 was set at 4.5\% per year in December 1998, and that has been confirmed in subsequent reviews. The ECB uses short-term interest rates for its operating target, so the growth in M3 is not an operating target, but rather growth in M3 is used to suggest risks to price stability.

The position of the ECB on the neutrality of money is also very clear from their website: "It is widely agreed that in the long run - after all adjustments in the economy have worked through - a change in the quantity of money in the economy will be reflected in a change in the general level of prices. But it will not induce permanent changes in real variables such as real output or unemployment."

This general principle, referred to as "the long-run neutrality of money", underlies most macroeconomic thinking. In the long term, real income and the level of employment are, essentially, determined by real factors, such as technology, population growth, or the preferences of economic agents.

The ECB website also makes clear that inflation is a monetary phenomenon: "In the long run a central bank can only contribute to raising the growth potential of the economy by maintaining an environment of stable prices. It 
cannot enhance economic growth by expanding the money supply or keeping short-term interest rates at a level inconsistent with price stability. It can only influence the general level of prices. Ultimately, inflation is a monetary phenomenon."

This suggests that the ECB incorporates the principles of the quantity theory of money in its analytical framework. The quantity theory is reviewed next, as the ECB apparently conceptually thinks that income velocity is stable enough to allow the use of the M3 monetary aggregate for guidance on medium-to-long term price-level changes.

\section{THEORY}

We start with Irving Fisher's (1922) equation of exchange. Fisher originally used transactions velocity, but we will use income velocity, so that

1) $\quad \mathrm{MV}=\mathrm{PQ}$

where, $\mathrm{M}$ is the nominal money stock, $\mathrm{V}$ is the income velocity of money, $\mathrm{P}$ is the average level of prices, and $\mathrm{Q}$ is aggregate real output. Differentiating with respect to time, we obtain as a first approximation

$\mathrm{dM} / \mathrm{dt}+\mathrm{dV} / \mathrm{dt}=\mathrm{dP} / \mathrm{dt}+\mathrm{dQ} / \mathrm{dt}$

Fisher believed velocity to be constant, so that the rate of price inflation, $\mathrm{dP} / \mathrm{dt}$, is a function of excess money growth. But, it is well known that the velocity of money is not permanent, but its movement over time may be predictable. If so, the implication would be that monetary authorities could use growth in the monetary aggregates as a useful predictor of inflation. Since the ECB does explicitly incorporate the use of monetary aggregates in its deliberations, the ECB apparently believes that velocity is stable.

obtain

However, making the standard Fisherian assumption that velocity is stable in the long run, or $\mathrm{dV} / \mathrm{dt}=0$, we

$\mathrm{dM} / \mathrm{dt}=\mathrm{dP} / \mathrm{dt}+\mathrm{dQ} / \mathrm{dt}$

In other words, changes in the money stock $\mathrm{M}$, cause proportionate changes in the price level $\mathrm{P}$ and/or changes in real output Q. Output growth depends on growth in productive factors and technological advancement. With a given resource pool and technology, the percentage change in output is predictable. Hence, strictly speaking, according to the differentiated quantity equation, the rate of growth in the current money supply determines the current inflation rate.

The microfoundation rationale for assuming velocity is stable can be seen by reforming equation 1) into the Marshallian money demand function. Define $\mathrm{k}=\mathrm{I} / \mathrm{V}$ and define $\mathrm{PQ}=\mathrm{Y}=$ nominal income. Then equation 1 ) becomes

4) $\mathrm{Md}=\mathrm{kY}$

Marshall's assertion that nominal money demand is strictly proportional to nominal income implies $\mathrm{k}$ is constant, or equivalently, that $\mathrm{V}$ is constant. As indicated, our premise is that velocity is not fixed, but that it may be predictable over time. A variable money demand, therefore, depends on factors other than income. Milton Friedman (1956) allows for other factors such as the returns on other assets relative to money to influence money demand. It is within that framework that we review the stability of income velocity. 


\section{ASSESSMENT}

We review the stability of income velocity for the EU within a Friedman framework of allowing for the return on other assets, or their price, to influence money demand. Stability is assessed for the following monetary aggregates - monetary base, M1, M2, and M3 -- with emphasis placed on M3, since the ECB focuses on this aggregate. Data available on the ECB website presented certain limitations in this analysis. Historical data on the monetary aggregates - M1, M2, and M3 -- start in 1980. Gross domestic product data, however, are only available starting in 1995. So income velocity data are only available since 1995. Data on the EU monetary base are only available from 1999. One would like to have additional data points on income velocity, especially, since Calza and Sousa (2003) suggest that there may be an aggregation effect on stability of money demand. But, the Treaty on the European Union wasn't signed until 1992. By January 1995, the EU had 15 members. In addition the euro wasn't introduced until December 1999, so income velocity data are perhaps only useful from 1995, or perhaps since 1999 when the euro was implemented in 11 countries.

\section{- Monetary Base}

The ECB states that it is the "... monopoly supplier of the monetary base ...." Likewise, other central banks, including the Federal Reserve, are the monopoly suppliers of their monetary base. Since Federal Reserve officials place little or no emphasis on the monetary aggregates, then, by implication, they must view the income velocity of aggregates as unstable or unpredictable. In contrast, since the ECB does place emphasis on at least the M3 aggregate, they must view income velocity as stable or predictable.

Behavior of the monetary-base income velocity is important within the quantity theory since the ECB is the monopoly supplier of its base. Income velocity (hereafter, velocity) of the monetary base has not been constant, as illustrated in Figure 1. Velocity increased as the 10-year euro benchmark yield increased, and then decreased this decade as yields fell as expected.

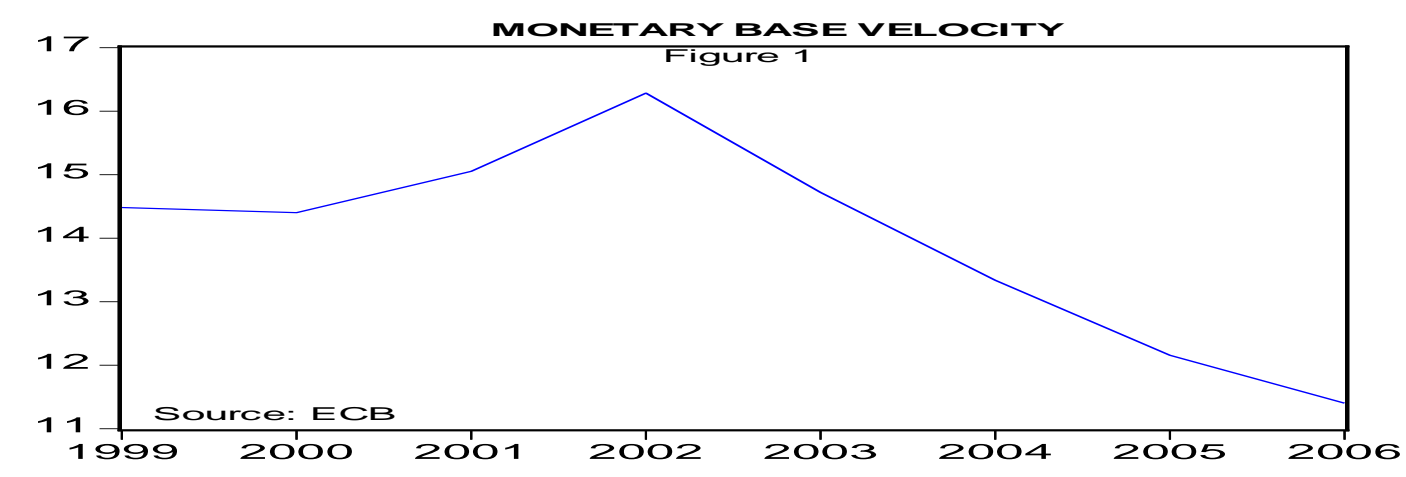

We use the 10-year euro benchmark bond yield as a proxy for both the price of the monetary base and the price of other monetary aggregates in this study. The AAA yield was used in the U.S. for the Anderson and Rasche (2001) study. The triple-A yield was also used in a study on money demand by Cosgrove, Singh, and Marsh (2007). This study, which focuses on the stability of money demand in the U.S., suggests that the monetary base and MZM appear to have a long-term stable relationship. However, money demand stability was not previously addressed for the shorter time frame that we use in this analysis.

The following relationship, Figure 2, shows the relationship between monetary base velocity and the loginverse of the 10-year euro benchmark yield. The scatter of observations for the short time frame - 1999 to 2006 suggests that a stable demand function may not exist. The ECB, however, does not officially use the behavior of the monetary base in their monetary deliberations. The simple correlation is 0.78 . But, as expected, the relationship does 
illustrate that an increase in bond yields, or increase in the price of money, results in an increase in monetary-base velocity.

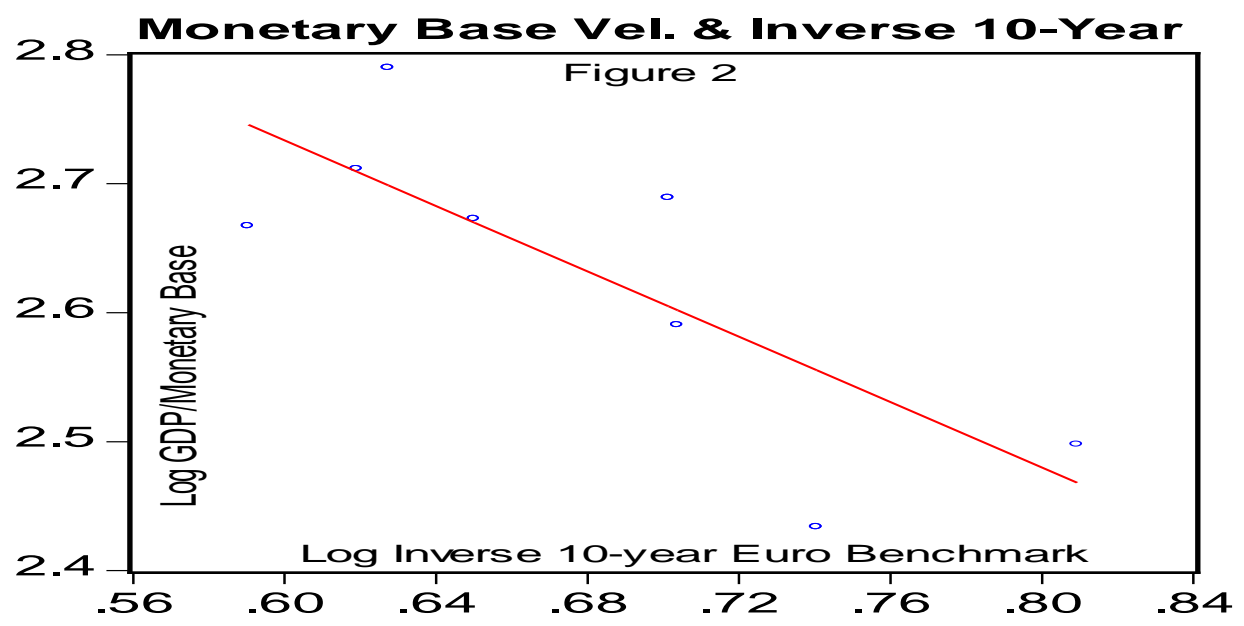

- $\quad$ M1

For the U.S., Lucas (1988) made the argument that M1 velocity was stable up to 1985 . Teles and Zhou (2005) concluded that the relationship estimated by Lucas held until the mid-1980s but not after that. Teles and Zhou suggested that perhaps the M1 measure of money was not a stable measure. Teles and Zhou used MZM, and concluded that the use of MZM provided evidence in support of a stable money demand for the U.S.

In this study, the relationship between M1 velocity and the log-inverse of the 10-year euro benchmark (Figure 3) provides some degree of support for a stable money demand function for the 1995 to 2006 period, but it is questionable if this is a linear relationship. From Figure 3, it doesn't appear one can claim that the relationship depicts a constant interest elasticity over the given time frame. But, at the same time, the simple correlation is 0.91 over this 10-year plus period. Perhaps, in the future, M1 will become a dependable measure of the transactions demand for money for the EU, and, therefore, real economic activity over the short term, as suggested by Scheller (2006.)

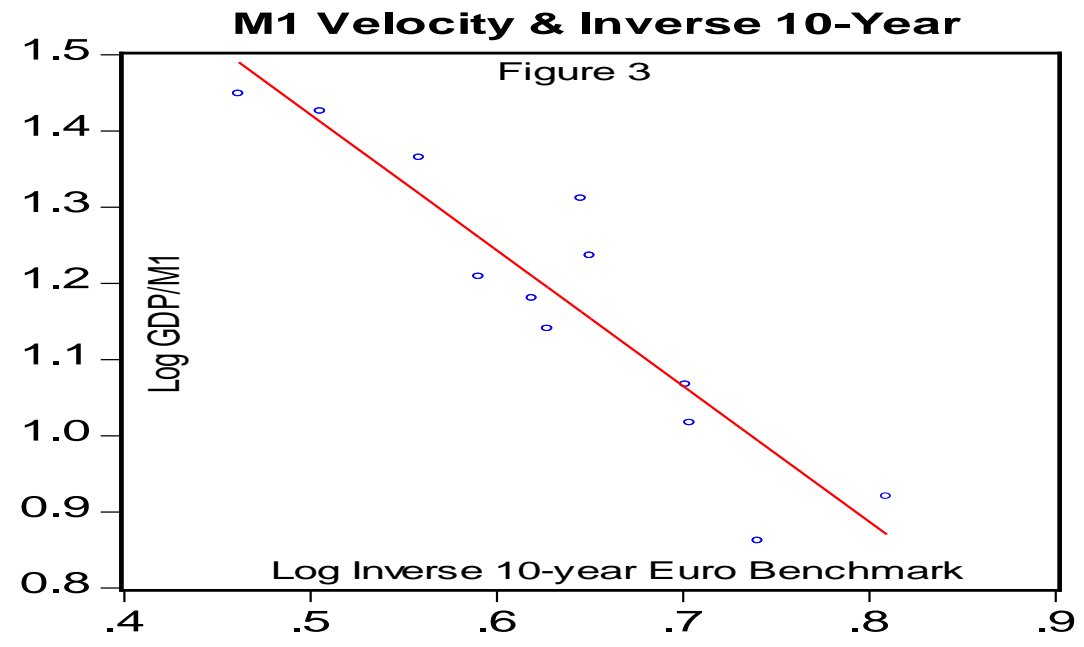


- $\quad$ M2

The relationship between M2 velocity and the log-inverse of the 10-year euro benchmark (Figure 4) is similar to Figure 3 in that it provides some degree of support for a stable money demand function, but, at the same time, the question remains if this is a linear relationship. Perhaps, given more time, this relationship may evolve into a pattern that the ECB monetary authorities consider dependable for benchmarking. Officially, the ECB does not use the behavior of M2 in its deliberations. Work by Hale and Jorda (2007) on M2 implies the ECB may also use M2.

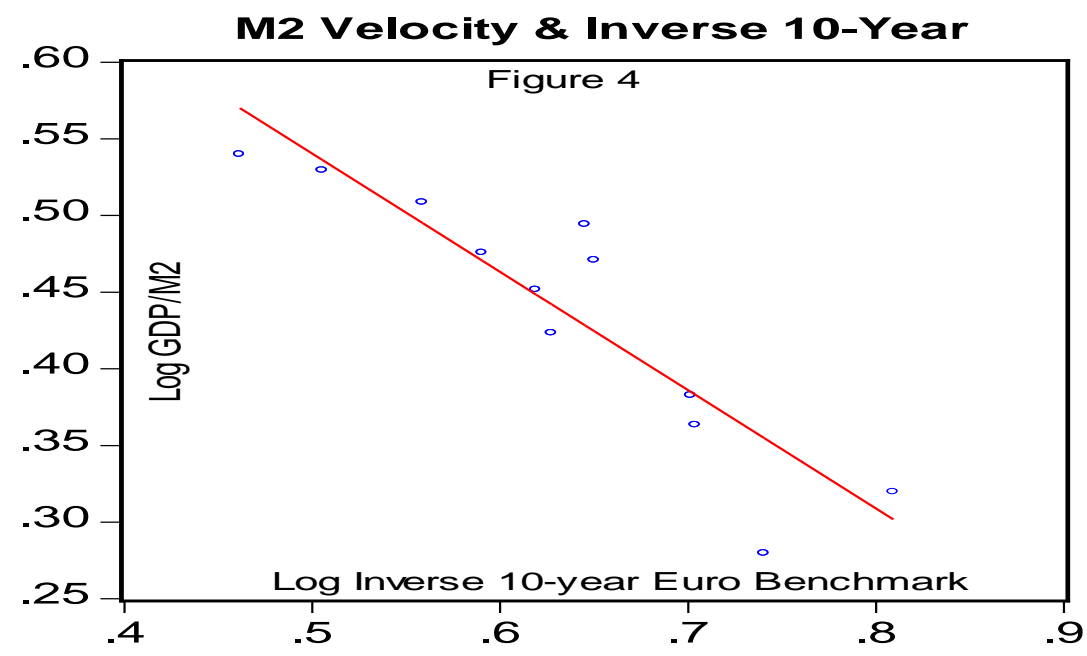

- $\quad$ M3

The ECB claims to make use of M3 in its monetary deliberations. The relationship between M3 velocity and the log-inverse of the 10-year euro benchmark (Figure 5) is somewhat similar to Figures 3 and 4 in that it provides some degree of support for a stable money demand function. But, clearly, a constant interest elasticity is not found.

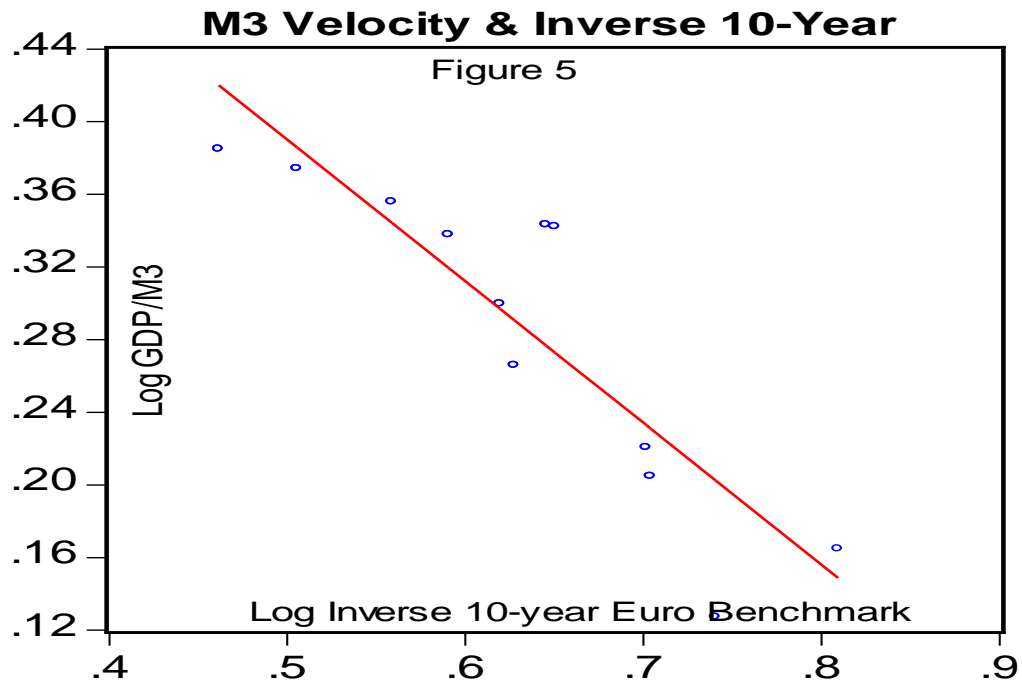


The M1, M2, and M3 aggregates are all suspect when it comes to using their behavior in ECB monetary deliberations. While providing some support for a stable money demand, these aggregates also provide some degree of support for a nonlinear relationship between individual aggregates and the 10-year euro benchmark.

\section{M3 GROWTH}

Jean-Claude Trichet, President of the ECB, in a July 23, 2007 interview stated that "The two pillar strategy has been very effective." The "two pillar strategy" Trichet refers to is explained in Scheller (2006.) One pillar involves analysis of the real economy, and the other pillar represents an analysis of the monetary side. Moreover, part of the monetary side involves use of M3. The reference target growth for M3 is 4.5\% per year which implies a potential GDP growth of $2.0 \%$ to $2.5 \%$ per year and a slowing in velocity of $0.5 \%$ to $1.0 \%$ per year to achieve price level stability according to Scheller (2006.) This relationship is expected to hold over the medium term. An article in the Financial Times (Atkins, 2007) a few days before the Trichet interview suggested that the ECB was demoting money supply in their inflation forecasts. But, the response by Trichet a few days later suggests otherwise.

A practical method for assessing the actual role of M3 in ECB deliberations is to view the MV side of the quantity theory of money. Clearly the M portion has been increasing in excess of the ECB reference target of 4.5\% per year during the current decade, Figure 6.

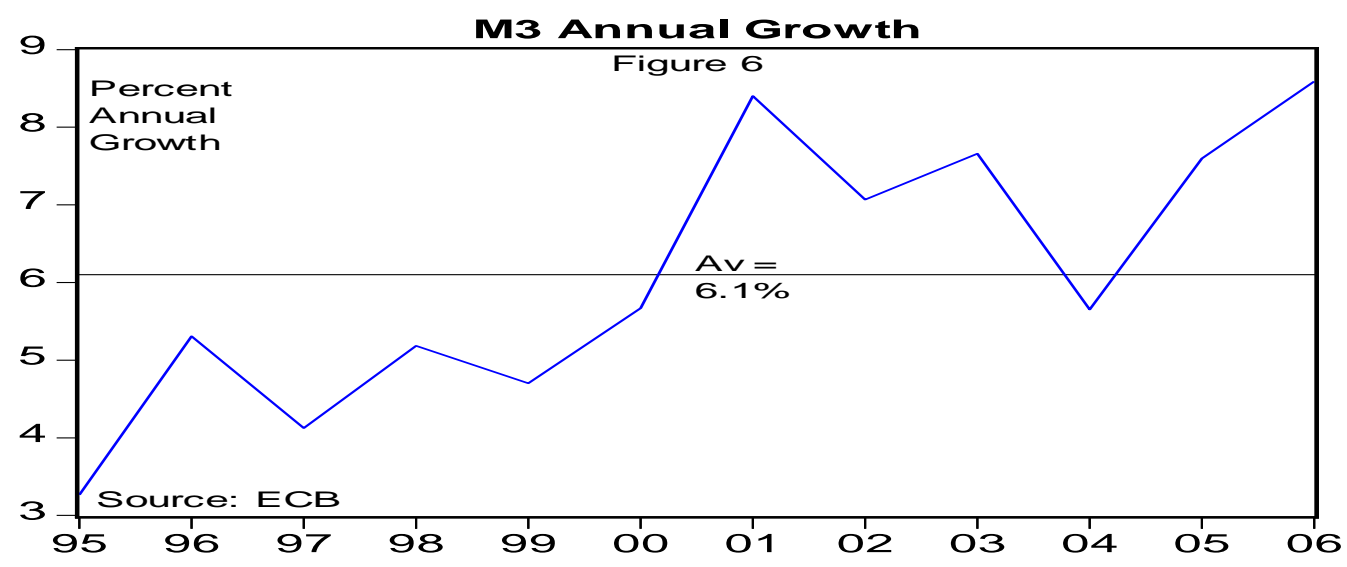

The rate of change in M3, however, when added to the rate of change in velocity (Figure 7) is approximately $4 \%$ per year, on average. The Figure 7 graph is only an approximation for MV.

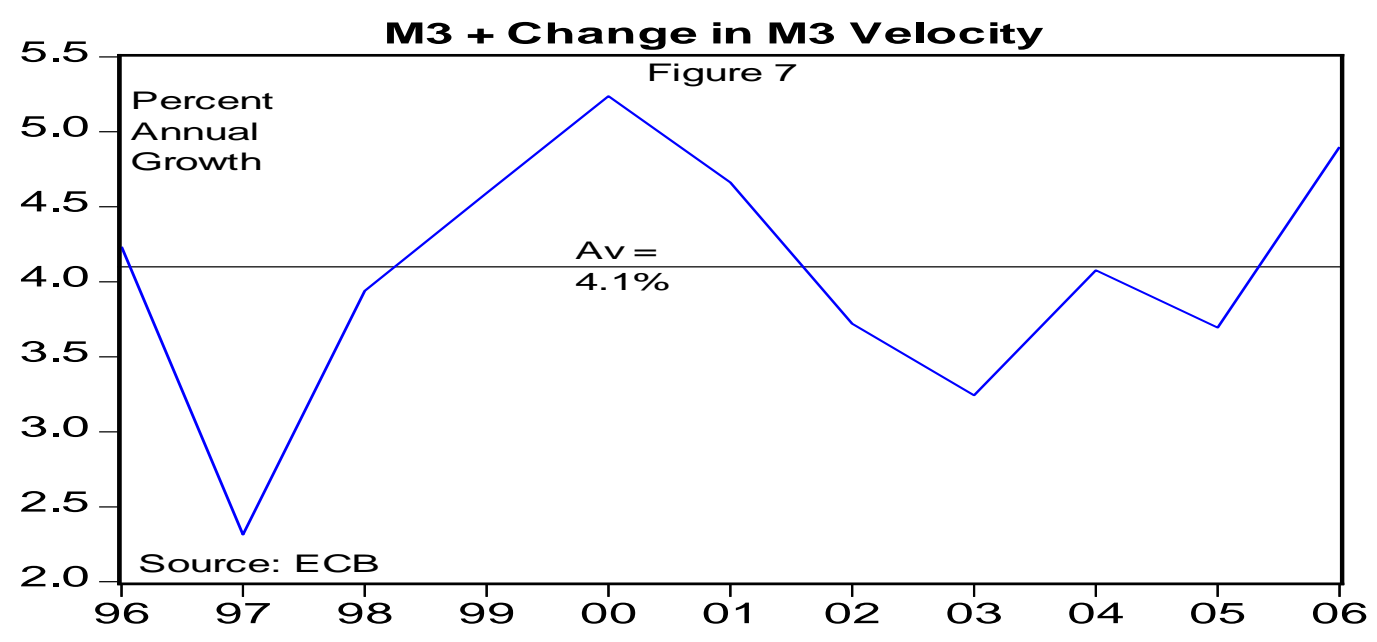


Potential real GDP of $2.0 \%$ to $2.5 \%$, therefore, implies a percentage change in the price level of around $2.0 \%$ per year. But this approximation to MV lends credence to the idea that the ECB could utilize the rate of change in MV (and not simply the rate of change in $\mathrm{M}$ ) as an indicator of medium to longer-term likely price pressures. This appears to be what the ECB is attempting according to Scheller (2006.)

\section{SUMMARY}

Our analysis suggests that the ECB approach of incorporating the growth of a monetary aggregate into the framework for medium-to-long term guidance of the direction of inflation pressures may have some merit. But, at the same time, our analysis suggests that one could also make the argument that a nonlinear relationship exists between velocity and the price of money. However, the MV portion of the quantity theory of money may hold some usefulness for the ECB which is the argument the ECB appears to be making.

\section{SUGGESTIONS FOR FUTURE RESEARCH}

A comparison of money demand stability in the EU and U.S. for similar time periods might be a useful research effort.

\section{REFERENCES}

1. Anderson, Richard and Rasche, Robert, The Remarkable Stability of Monetary Base Velocity in the United States, 1919-1999, The Federal Reserve Bank of St. Louis, Working Paper 2001-008, (August), 2001.

2. Atkins, Ralph, ECB demotes money supply in inflation forecasts, Financial Times, July 13, 2007.

3. Calza, Alessandro and Sousa, Joao, Why has Broad Money Demand been more Stable in the Eruio Area than in other Economies: A Literature Review, European Central Bank, Working Paper No. 261, (September), 2003.

4. Cosgrove, Michael, Singh, Chaitanya and Marsh, Daniel, Money Demand Stability and Central Banks, forthcoming publication in the Journal Academy of Business and Economics.

5. European Central Bank, http://www.ecb.int/mopo/intro/html/role.en.html

6. Fisher, Irving, The Purchasing Power of Money, Macmillan, First Edition, New York, 1911.

7. Friedman, Milton, The Quantity Theory of Money: A restatement, in M. Friedman, editor, Studies in the Quantity Theory of Money. University of Chicago Press, Chicago, 1956.

8. Hale, Galina and Jorda, Oscar Do Monetary Aggregates Help Forecast Inflation? FRBSF Economic Letter, Federal Reserve Bank of San Francisco, April 13, 2007.

9. Lucus, Robert, Jr., Money Demand in the United States: A quantitative review, Carnegie-Rochester Conference Series on Public Policy, Vol. 29, 1988.

10. Scheller, Hanspeter K., The European Central Bank, History, Role and Functions, European Central Bank, Second revised edition, 2006.

11. Teles, Pedro and Zhou, Ruilin, A stable money demand: Looking for the right monetary aggregate, Economic Perspectives, Federal Reserve Bank of Chicago, Quarter 1, 2005.

12. Trichet, Jean-Claude, Interview conducted by Marc Brost and Robert von Heusinger, European Central Bank, Press and Information Division, July 23, 2007. 
NOTES 